\title{
Atypical subtrochanteric femoral shaft fractures: role for mechanics and bone quality
}

\author{
Marjolein $\mathrm{CH}$ van der Meulen ${ }^{1, *}$ and Adele L Boskey ${ }^{2}$
}

\begin{abstract}
Bisphosphonates are highly effective agents for reducing osteoporotic fractures in women and men, decreasing fracture incidence at the hip and spine up to $50 \%$. In a small subset of patients, however, these agents have recently been associated with 'atypical femoral fractures' (AFFs) in the subtrochanteric region or the diaphysis. These fractures have several atypical characteristics, including occurrence with minimal trauma; younger age than typical osteoporotic fractures; occurrence at cortical, rather than cancellous sites; early radiographic appearance similar to that of a stress fracture; transverse fracture pattern rather than the familiar spiral or transverse-oblique morphologies; initiation on the lateral cortex; and high risk of fracture on the contralateral side, at the same location as the initial fracture. Fracture is a mechanical phenomenon that occurs when the loads applied to a structure such as a long bone exceed its load-bearing capacity, either due to a single catastrophic overload (traumatic failure) or as a result of accumulated damage and crack propagation at sub-failure loads (fatigue failure). The association of AFFs with no or minimal trauma suggests a fatigue-based mechanism that depends on cortical cross-sectional geometry and tissue material properties. In the case of AFFs, bisphosphonate treatment may alter cortical tissue properties, as these agents are known to alter bone remodeling. This review discusses the use of bisphosphonates, their effects on bone remodeling, mechanics and tissue composition, their significance as an effective therapy for osteoporosis, and why these agents may increase fracture risk in a small population of patients.
\end{abstract}

*Correspondence: mcv3@cornell.edu

'Sibley School of Mechanical and Aerospace Engineering, Cornell University, 219 Upson Hall, Ithaca, NY, USA

Full list of author information is available at the end of the article

\section{Atypical fractures: what they are and their incidence}

The first case report describing atypical fractures of the femur was published in 2005 and reported on nine adults receiving bisphosphonate treatment [1]. Since that time, the number of case reports has increased markedly, and the existence of atypical femoral fractures (AFFs) is now widely accepted. The incidence remains low, but substantial mortality is associated with these fractures. Little is known regarding their etiology and mechanism. The measurable factors and individual characteristics contributing to AFF development in particular individuals require further investigation given the large number of postmenopausal women on these agents [2].

In 2009, the American Society of Bone and Mineral Research (ASBMR) appointed a task force to summarize the current state of knowledge and address key questions about AFFs. Based on a comprehensive literature review and the experiences of clinical experts on the task force, a case definition was generated (Table 1 of [3]). To define a fracture as an AFF, the following five major features must be present (Figure 1): 1) location along the femur distal to the lesser trochanter and proximal to the supercondylar flare; 2) minimal or no trauma at fracture; 3) transverse or short oblique fracture configuration; 4) lack of comminution; and 5) complete fractures extend through both cortices and may be associated with a medial 'spike' or incomplete fractures involve only the lateral cortex. An additional seven 'minor features' are often reported but are not required for classifi cation as an AFF, including a lateral periosteal reaction, cortical thickening, prodromal symptoms and bilateral incidence. Combined these criteria suggest contributing biomechanical factors include whole bone geometry and material properties [4,5], as described below.

While no direct causation has been established, AFFs are often associated with long-term bisphosphonate treatment. In the 310 case reports examined by the ASBMR task force, 291 of the published reports (94\%) identified bisphosphonate use as a comorbidity, with a mean treatment duration of 7 years. While this association is present in case reports, a similar connection has not been established in the phase III clinical trial data ([6] and see 


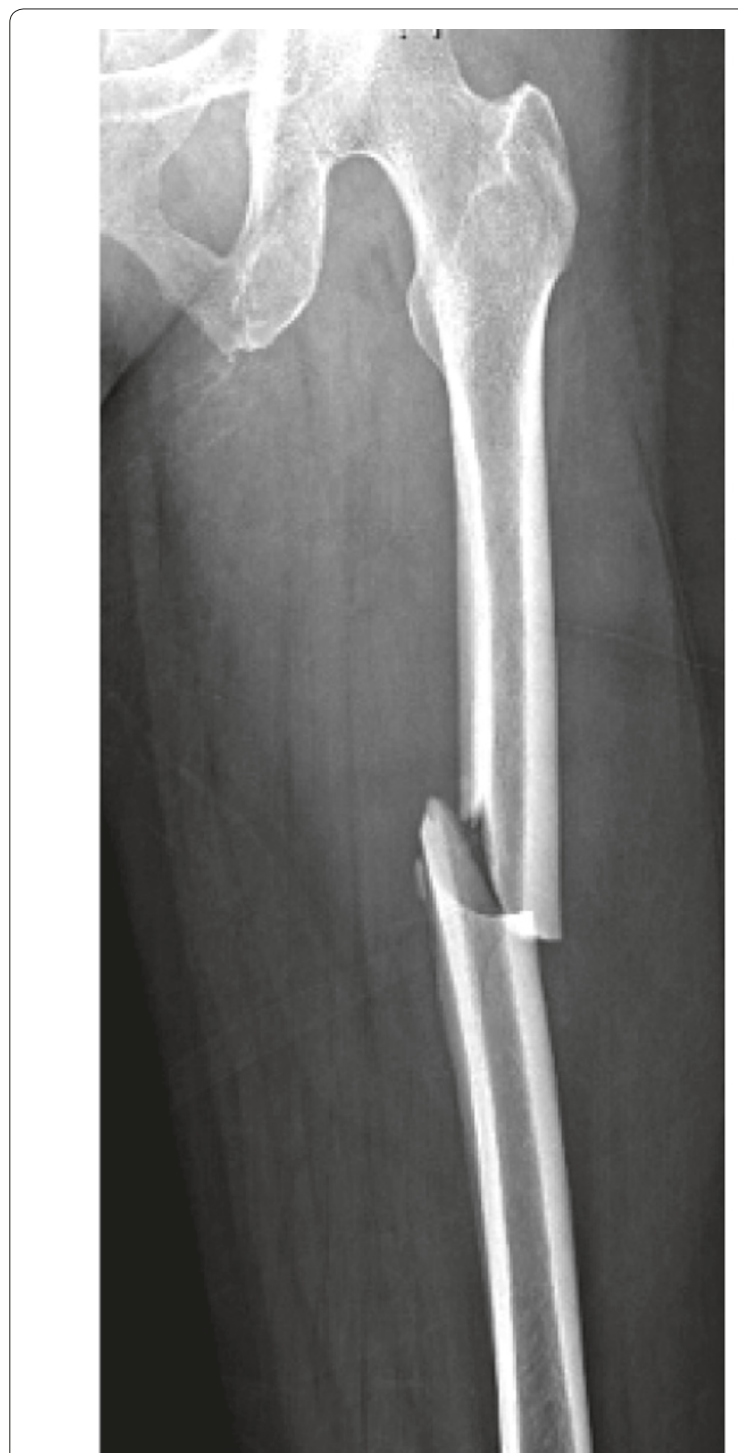

Figure 1. Radiograph of a middiaphyseal atypical femoral fracture (59-year-old female, 7 years of alendronate treatment).

discussion in [7]). This apparent discrepancy may reflect the strict inclusion criteria for bisphosphonate treatment in the phase III trials and characteristics of the clinical trials that limited the treatment duration in the placebocontrolled studies. In addition, Black and colleagues [6] did not evaluate fractures radiographically to confirm the location and atypia, as has been the standard methodology for all recent case reports.

Larger population-based studies have drawn conclusions both for and against the association of AFFs with bisphosphonate use. In a Danish cohort study based on examining only medical records, not radiographs, the risk of hip and subtrochanteric or femoral shaft fractures was increased in bisphosphonate-treated (alendronate) patients [8]. However, individuals with greater cumulative bisphosphonate doses did not have greater risk of AFFs than individuals exposed to smaller doses, leading the authors to conclude that osteoporosis could be the underlying cause of the fractures. Risk for subtrochanteric or femoral shaft fractures was associated with bisphosphonate treatment for more than 5 years in a case control study of a large population-based cohort of elderly women (aged 68 years or older at initiation of bisphosphonates) [9]. The risk of typical osteoporotic femoral neck or intertrochanteric fractures was reduced in the same population with long-term bisphosphonate treatment, as would be expected; 716 AFF patients were included, with 3,580 matched controls. All diagnoses were medical record-based; no radiographs were examined in this study.

\section{Bisphosphonates}

Bisphosphonates are used to treat osteoporosis by targeting bone resorption and reduce fracture rates in the spine by 40 to $50 \%$. Two primary mechanisms contribute to their efficacy: affinity for binding to bone mineral and inhibition of osteoclast function [10]. The coupling of bone resorption and formation in remodeling leads to an overall reduction in bone turnover with bisphosphonate treatment. Quantitatively, reductions in bone turnover do not map directly to reduced fracture risk, nor do increases in bone mass fully explain reductions in fracture incidence with bisphosphonate treatment.

Bisphosphonates are chemically stable analogues of pyrophosphate compounds, first introduced into clinical practice 50 years ago in 1962 [11]. All bisphosphonates contain non-hydrolysable P-C-P bonds. They can be divided into different classes based on structure: those with aliphatic chains (etidronate or clodronate) and the $\mathrm{N}$-containing bisphosphonates; those containing nitrogen as part of the aliphatic chain (neridronate, alendronate and ibandronate); or those containing one or more five- or six-membered rings (risedronate, zolendronate and mindronate). The structures and functions of the major bisphosphonates in clinical use were reviewed recently [12]. The mechanisms of action of the first generation, aliphatic chain bisphosphonates and the Ncontaining bisphosphonates are very different. Both bind with high affinity to bone mineral (hydroxyapatite) [13], but first generation bisphosphonates, such as etidronate and clodronate, bind directly to analogues of ATP forming ATP-P-C-P complexes, preventing ATP hydrolysis and leading to cell death $[11,14]$. The $\mathrm{N}$-containing bisphosphonates, in contrast, inhibit farensyl pyrophosphate synthase activity, preventing the prenylation of proteins required for cell function and survival and leading to premature apoptosis in the exposed cells [11]. Since the osteoclast is the cell exposed to the majority of the bisphosphonates retained in bone, bisphosphonates 
result in osteoclast cell death, and hence inhibit bone remodeling. The loss of osteoclasts, in turn, can affect osteoblast activity as these processes are coupled. Osteoclasts can be rescued from the apoptosis-inducing effects of the bisphosphonates by inducing expression of anti-apoptotic factors [14]. Osteoblasts and osteocytes can also become apoptotic via a similar mechanism, depending on the bisphosphonate used, which would also impact new bone formation [15].

Zolendronate is the bisphosphonate with the greatest in vitro affinity for hydroxyapatite, followed by pamidronate, alendronate, ibandronate, risedronate, etidronate and clondronate, with clondronate having the least affinity [13]. Each of these compounds has been used in clinical trials to treat osteoporosis [16] and non-skeletal diseases [17]. Osteoporosis is a disease characterized by increased fracture risk as a result of an imbalance between bone formation (by osteoblasts and osteocytes) and bone resorption (by osteoclasts). The outcome assessments most frequently used to judge therapeutic efficacy are: changes in bone mineral density (BMD; or bone quantity as assessed by dual energy X-ray absorptiometry (DXA)); bone turnover markers, such as $\mathrm{N}$ - and $\mathrm{C}$ collagen telopeptide cross-link breakdown products, bone-specific alkaline phosphatase, osteocalcin or hydroxyproline; dynamic histomorphometric measures of mineral deposition rate (which require a biopsy); and fracture incidence in large clinical studies.

Generally, bone turnover markers decrease and BMD increases in large clinical trials but differences exist by specific agent, skeletal site and individual response. In clinical trials, BMD in patients treated with bisphosphonates increased at 1 and 3 years [16]. In general, changes are greater at the spine than in the hip or femoral neck. BMD increases due to filling in of remodeling space and continued secondary mineralization of pre-existing bone tissue. To complicate the story, different drugs act at different rates (for example, zoledronic acid is reported to have more rapid effects than alendronate [16]), but, on average, bisphosphonate therapies effectively reduce bone turnover. Overall, bisphosphonates can improve bone properties and reduce fracture risk [6,18-20] as evident from improved histomorphometric parameters [21], decreased changes in bone turnover markers [22], and increased BMD [23].

Quantitatively, reductions in bone turnover do not map directly to reduced fracture risk, nor do increases in bone mass fully explain reductions in fracture incidence with bisphosphonate treatment. Antiresorptive treatments produce modest increases in areal bone mineral density, ranging from 0 to $8 \%$, yet reduce fracture risk by 30 to $50 \%$ [24-26]. This disproportionate decrease in fracture incidence [27] suggests altered tissue material characteristics are likely a contributing factor to the efficacy of these therapies in osteoporotic patients. By preventing trabecular plate perforation, bisphosphonates may prevent the cancellous microarchitectural deterioration that leads to osteoporotic fractures.

Despite these positive effects on fracture risk, many questions remain concerning bisphosphonate use. Some issues are obviously related to patient compliance [16], but the more relevant ones concern prescribing of bisphosphonates: who are appropriate patients and how long should treatment be continued. Is a 'bone holiday', in which bisphosphonate treatment is suspended for 5 or 10 years, a good recommendation? Are other drugs as effective in reducing fracture risk? It is beyond the scope of this review and of the basic science authors to make recommendations in response to these questions, but a few facts can be pointed out. In a meta-analysis of patients who discontinued bisphosphonates for 5 years after 5 years of treatment, with only three eligible studies, fracture risk was not different between the two groups [28]. This result may reflect the retention of the bisphosphonates within the bone due to their high affinity for hydroxyapatite. In fact, in patients on $10 \mathrm{mg} /$ day of alendronate for 5 years the drug exposure remains at $25 \%$ of the original dose in the 5 years after treatment is stopped [29]. Because AFFs may be associated with 'prolonged' bisphosphonate use, we will consider the known effects of short- and long-term bisphosphonate treatments on bone mechanics and bone quality. Other reported complications of bisphosphonate use are reviewed elsewhere [30].

\section{Mechanics}

From a mechanics perspective, the five major features outlined by the ASBMR task force to define AFFs provide insights into potential mechanisms contributing to fracture [3]. Minimal or no trauma, a required feature, suggests that AFFs result from repetitive loading (fatigue fracture) rather than a single overload (traumatic fracture). This conclusion is further confirmed by the frequent presence of a periosteal reaction and prodromal symptoms, both minor features. Characteristics of long bones known to contribute to the development of skeletal stress fractures (fatigue fractures) are whole bone structure and applied loading [31-33]. Once damage has been initiated, cracks propagate and coalesce to produce structural failure and fracture, a process that depends on cortical cross-sectional geometry and tissue material properties.

The frequent bilateral incidence of AFFs, a minor feature, also suggests a strong mechanical etiology associated with individual anatomy. Differences in whole bone geometry relative to non-fractured controls, such as the femoral neck shaft angle and femoral curvature [4], can alter the stresses and strains produced in the cortical diaphysis with loading and may contribute to fracture 
incidence. The existence of whole bone structural differences between individuals with and without AFFs needs to be determined and, if present, related to bone tissue level strains and stresses and stress fracture development.

The transverse fracture configuration, another major feature, suggests that the material properties of bone tissue are altered in individuals with AFFs. The femur experiences high bending and torsional loads that normally produce oblique or spiral fracture configurations due to the applied loading and well-documented mechanical properties of cortical bone [5]. Bone tissue is weaker in tension than compression, and this asymmetry is reflected in the morphology of the fracture surface. Altered mechanical properties, such as increased tissue brittleness, would further alter fracture morphology. Comorbidities associated with AFFs, such as bisphosphonate therapy, could contribute to such alterations in tissue properties and bone quality.

Limited data are available on the effects of bisphosphonate treatment on bone tissue properties, particularly for cortical bone where AFFs occur. The majority of preclinical studies examining material properties of cortical tissue were performed in canine models without estrogen deficiency and using supraphysiological bisphosphonate doses (see review by Allen and Burr [34]). In addition, more data are available on cancellous bone than on cortical bone, given the osteoporosis emphasis of these treatments. In cortical bone, bisphosphonate treatment generally does not alter bone material strength and stiffness, but high doses decrease post-yield toughness [35-37]. Post-yield toughness was reduced $28 \%$ with alendronate $(1.0 \mathrm{mg} / \mathrm{kg})$ and $51 \%$ with risedronate $(0.5 \mathrm{mg} / \mathrm{kg})$ in the healthy canine tibia after 1 year [37], $19 \%$ with alendronate in the canine rib after 1 year [38], and $34 \%$ with alendronate in the canine rib after 3 years [36]. However, material property changes were not present in the canine femoral diaphysis after 1 and 3 years of alendronate treatment. Finally, nanomechanical analysis of iliac crest biopsies showed no differences in cortical modulus in tissue from AFF patients relative to agematched and young female controls [39]. These data suggest that the tissue elastic behavior is not altered with bisphosphonate treatment but cannot measure toughness or fatigue properties. Considered in terms of fracture mechanics, the transverse fractures seen clinically suggest increased damage and reduced deformation post-yield that lead to a brittle fracture of the femur.

\section{Bone quality}

Bisphosphonates increase the quantity or amount of bone (BMD), but tissue quality contributes to fracture risk as well. Bone quality, as reviewed recently [40], includes properties beyond bone mass that contribute to bone mechanical strength, and hence fracture risk. These properties include bone geometry (the shape and size of bone), architecture (the arrangement of the structures within the bone), collagen maturity (collagen cross-links and advanced glycation products), the presence of microdamage, and the properties of the mineral, including its distribution, composition, orientation, crystal size and perfection. Each of these characteristics correlates to either fracture risk or bone strength, or both.

\section{Cortical geometry}

Both whole bone morphology and cross-sectional geometry of the femur determine the mechanical environment in the cortex and can predispose the hip to fracture $[4,41]$. Military recruits who present with stress fractures have smaller cross-sectional geometry than those who do not fracture [31]. In addition, bone tissue quality may be linked with whole bone morphology. In a small sample, the cortical tissue of slender male tibiae was more brittle and damage-prone than the cortex of wider bones [33]. In the spine, fracture risk was associated with crosssectional geometry [42].

The ASBMR task force included localized periosteal reaction and generalized cortical diaphyseal thickening as minor features of AFF [3]. Reports of AFF often do not distinguish between cortical thickening and periosteal stress reaction. Increased cortical thickness has been noted with AFF $[3,43]$.

Whether bisphosphonates alter cortical geometry is unclear. At corticocancellous sites, the cortical shell thickness and area increases in osteoporotic women with bisphosphonate treatment $[44,45]$. For example, risedronate increased the cross-sectional moment of inertia and cross-sectional area of the femur in osteoporotic and osteopenic women and men after 4, 8, and 12 months of treatment [44]. In a recent report, however, cortical thickness of the femoral diaphysis was not increased with alendronate treatment for at least 5 years when measured by DXA [46], but DXA has limitations for measuring cortical thickness [47]. Thus, the effects of bisphosphonates on cortical architecture remain to be elucidated, and if present, geometric effects may also be accompanied by alterations of other tissue properties.

\section{Collagen}

Three fundamental properties of the collagen network influence mechanical properties [48]: the amount of collagen; the fibril orientation [49]; and its maturity (post-translational modification of the collagen). Collagen fibrils are formed from triple-helical collagen molecules. With age, the stability of the collagen fibrils increased by forming intra- and inter-fibrillar cross-links. Some cross-links are derived by enzymatic pathways through which collagen lysyl and hydroxylysyl groups form five- and six-membered rings with other amino 
acids; these enzymatic cross-links may be non-reducible (more stable) or reducible. A second type of cross-link is derived by non-enzymatic glycosylations [50]. The presence of both types of cross-links can be determined biochemically or inferred from spectroscopic correlates.

Mechanical properties have been correlated with the number of non-enzymatic glycosylations [50] and enzymatic cross-links [51]. In animal models with chemically altered collagen cross-links and in osteoporotic human specimens higher ratios of non-reducible/reducible cross-links are associated with increased bone stiffness and strength [52,53]. In contrast, increased concentration of non-enzymatic cross-links with aging correlated with decreased bone strength [53].

Bisphosphonates have been reported to increase the amount of non-enzymatic cross-links without changing the number of enzymatic cross-links. Compared to placebo, risedronate retained baseline values of collagen cross-links, measured by infrared imaging, in active bone-forming areas, returning to premenopausal values after 5 years of treatment [54]. In a preclinical healthy canine model, reductions in post-yield toughness of cortical tissue with high doses of bisphosphonates were associated with increased non-enzymatic collagen glycation [37].

\section{Microdamage}

Loading of bone creates damage in the form of cracks. Fracture resistance partially depends on the ability of bone to remodel and repair microscopic cracks or microdamage before they lead to failure. Longer cracks are associated with weaker bone [55]. Reducing bone turnover could affect damage repair and damage accumulation, particularly given that AFFs are likely fatigue fractures. Increased crack lengths and density accompanied reductions in post-yield toughness of cortical bone with high dose bisphosphonate treatment $[36,38]$. Clinically, however, the number of microcracks and their frequency was low in postmenopausal osteoporotic women and not altered in iliac crest biopsies from women on bisphosphonates relative to untreated control biopsies [56]. These clinical data are for cancellous tissue, however, and data are needed for the cortex. The question of whether microcrack initiation and repair is suppressed by bisphosphonates remains open, especially in cortical bone.

\section{Mineralization}

The amount of mineral present and its alignment, distribution and characteristics, such as chemical composition, and crystal size and orientation, contribute to the mechanical function of the mineralized tissue and fracture risk, and may in part help explain the AFF phenotype. In mice of different ages, significant positive correlations were observed between the elastic modulus and the compositional properties determined by infrared imaging, including mineral/matrix ratio and crystallinity [57]. In multiple linear regressions of mineral properties from 52 individuals with and without fracture, increases in three parameters were significantly associated with increased fracture risk: cortical and cancellous collagen maturity; cortical mineral/matrix ratio; and cancellous crystallinity [58].

Bisphosphonate treatment has multiple effects on mineral properties. Risedronate for 3 and 5 years maintained material properties in iliac crest biopsies of treated postmenopausal women, while mineral content and crystallinity increased in placebo groups [54]. These matrix material changes were thought to contribute to risedronate's rapid and sustained antifracture efficacy in osteoporotic patients [54]. Similarly, based on Raman spectroscopic analysis, a study of biopsies from women treated with zolendronate once yearly over a 3-year period showed an increased mineral/matrix ratio compared with placebo and resulted in smaller mineral crystallites that are characteristic of younger bone [59].

Tissue heterogeneity is reduced with bisphosphonate treatment as measured by Fourier transform infrared spectroscopy imaging. Following short-term treatment with alendronate, iliac crest biopsies from perimenopausal woman had decreased compositional parameter distributions (heterogeneity) relative to untreated controls [60]. Similar results were found in a normal, non-osteopenic animal model treated with either risedronate or alendronate [61]. In biopsies obtained adjacent to hip fracture site in bisphosphonate-treated women, including some with AFFs, the heterogeneity of the compositional parameters also decreased compared to bisphosphonate-naïve women, while the mean property values were similar [49]. Interestingly, the cortical mineral/matrix ratio was $8 \%$ greater in tissue from patients with atypical subtrochanteric fractures than that of patients with typical fractures. The reduced mineral and matrix heterogeneity may diminish tissue-level toughening mechanisms that normally inhibit crack propagation. Altered tissue mineralization has been implicated in bisphosphonate treatment $[62,63]$ and needs to be related to tissue mechanical performance.

\section{Conclusion}

The concern of whether long-term bisphosphonate use oversuppresses bone turnover contributing to AFF remains open. Those patients who suffer AFF appear to have unique compositional characteristics, which could indicate pre-existing qualities prior to the initiation of bisphosphonate therapy or a property that occurs in a limited number of patients as a result of bisphosponate treatment. The suggestion of a bisphosphonate holiday in 
which treatment is stopped for short periods of time to avoid AFF formation is controversial because the successful return to 'normal' remodeling needs to be demonstrated. Retention of bisphosphonates in the bone matrix may result in residual release for more than 7 years $[13,64]$.

Evidence is mixed regarding the contribution of oversuppression of bone turnover with bisphosphonate treatment to AFF initiation. Limited histological analyses have been performed on tissue from individuals with AFFs to support the mechanisms suggested above. Severely suppressed bone turnover was evident based on the absence of double fluorochrome labels in iliac crest biopsies from patients with AFFs $[1,65]$. In a case report, tissue from the femur and iliac crest demonstrated increased resorption and decreased formation in a 76-year-old woman with a femoral fracture [66]. In tissue removed at the fracture site during intramedullary nail insertion in a 57-year-old woman, evidence of bone remodeling was present; however, a great number of empty osteocytic lacunae were evident, as was necrotic and damaged tissue at the fracture site [67]. In all cases, the presence of a clear fracture callus and radiolucency at the site of fracture initiation suggests that bone tissue can still be actively formed and resorbed in these individuals, although local demineralization is also a possible mechanism.

In conclusion, insufficient evidence exists on the specific effects of bisphosphonates on cortical bone quality and tissue properties, and their effects on the mechanical performance of the skeleton. Based on current knowledge, bisphosphonates remain a safe and effective therapy to prevent fractures in osteoporotic individuals. Further investigation into the origin of AFFs is required, along with better methods to detect those few patients at risk for developing this major complication.

This article is part of the series on Cutting edge topics and advances in orthopaedic research, edited by Edward Schwarz and Jay Lieberman. Other articles in this series can be found at http://arthritis-research.com/series/orthopaedics

\section{Abbreviations}

AFF, atypical femoral fracture; ASBMR, American Society of Bone and Mineral Research; BMD, bone mineral density; DXA, dual energy $\mathrm{x}$-ray absorptiometry.

Competing interests

The authors declare that they have no competing interests.

\section{Acknowledgments}

We thank Drs Susan Bukata and Joseph Lane for organizing the workshop at the Orthoapedic Research Society annual meeting in Long Beach, CA, that was the basis for this article. We thank Drs JM Lane and A Potty for the radiograph. Funding was provided by NIH R01-AR041325, R01-AR053571 and P30-AR046121.

\section{Author details}

'Sibley School of Mechanical and Aerospace Engineering, Cornell University, 219 Upson Hall, Ithaca, NY 14853, USA. ${ }^{2 H o s p i t a l}$ for Special Surgery, Weill Medical College of Cornell University, 535 E. 70th Street, New York, NY 10021, USA.

\section{Published: 29 August 2012}

\section{References}

1. Odvina CV, Zerwekh JE, Rao DS, Maalouf N, Gottschalk FA, Pak CY: Severely suppressed bone turnover: a potential complication of alendronate therapy. J Clin Endocrinol Metab 2005, 90:1294-1301.

2. Siris ES, Pasquale MK, Wang Y, Watts NB: Estimating bisphosphonate use and fracture reduction among US women aged 45 years and older, 2001-2008. J Bone Miner Res 2011, 26:3-11.

3. Shane E, Burr D, Ebeling PR, Abrahamsen B, Adler RA, Brown TD, Cheung AM, Cosman F, Curtis JR, Dell R, Dempster D, Einhorn TA, Genant HK, Geusens P, Klaushofer K, Koval K, Lane JM, McKiernan F, McKinney R, Ng A, Nieves J, O'Keefe R, Papapoulos S, Sen HT, van der Meulen MC, Weinstein RS, Whyte M; American Society for Bone and Mineral Research: Atypical subtrochanteric and diaphyseal femoral fractures: report of a task force of the American Society for Bone and Mineral Research. J Bone Miner Res 2010, 25:2267-2294.

4. Wang Q, Teo JW, Ghasem-Zadeh A, Seeman E: Women and men with hip fractures have a longer femoral neck moment arm and greater impact load in a sideways fall. Osteoporos Int 2009, 20:1151-1156.

5. Reilly DT, Burstein AH: The elastic and ultimate properties of compact bone tissue. J Biomech 1975, 8:393-405.

6. Black DM, Kelly MP, Genant HK, Palermo L, Eastell R, Bucci-Rechtweg C, Cauley J, Leung PC, Boonen S, Santora A, de Papp A, Bauer DC; Fracture Intervention Trial Steering Committee; HORIZON Pivotal Fracture Trial Steering Committee: Bisphosphonates and fractures of the subtrochanteric or diaphyseal femur. NEng/ J Med 2010, 362:1761-1771.

7. Rizzoli R, Akesson K, Bouxsein M, Kanis JA, Napoli N, Papapoulos S, Reginster $J Y$, Cooper C: Subtrochanteric fractures after long-term treatment with bisphosphonates: a European Society on Clinical and Economic Aspects of Osteoporosis and Osteoarthritis, and International Osteoporosis Foundation Working Group Report. Osteoporos Int 2011, 22:373-390.

8. Abrahamsen B, Eiken P, Eastell R: Cumulative alendronate dose and the long-term absolute risk of subtrochanteric and diaphyseal femur fractures: a register-based national cohort analysis. J Clin Endocrinol Metab 2010, 95:5258-5265.

9. Park-Wyllie LY, Mamdani MM, Juurlink DN, Hawker GA, Gunraj N, Austin PC, Whelan DB, Weiler PJ, Laupacis A: Bisphosphonate use and the risk of subtrochanteric or femoral shaft fractures in older women. JAMA 2011, 305:783-789.

10. Russell RG, Watts NB, Ebetino FH, Rogers MJ: Mechanisms of action of bisphosphonates: similarities and differences and their potential influence on clinical efficacy. Osteoporos Int 2008, 19:733-759.

11. Russell RG: Bisphosphonates: the first 40 years. Bone 2011, 49:2-19.

12. Ebetino FH, Hogan AM, Sun S, Tsoumpra MK, Duan X, Triffitt JT, Kwaasi AA, Dunford JE, Barnett BL, Oppermann U, Lundy MW, Boyde A, Kashemirov BA, McKenna CE, Russell RG: The relationship between the chemistry and biological activity of the bisphosphonates. Bone 2011, 49:20-33.

13. Nancollas GH, Tang R, Phipps RJ, Henneman Z, Gulde S, Wu W, Mangood A, Russell RG, Ebetino FH: Novel insights into actions of bisphosphonates on bone: differences in interactions with hydroxyapatite. Bone 2006, 38:617-627.

14. Rogers MJ, Crockett JC, Coxon FP, Monkkonen J: Biochemical and molecular mechanisms of action of bisphosphonates. Bone 2011, 49:34-41.

15. Bellido T, Plotkin Ll: Novel actions of bisphosphonates in bone: preservation of osteoblast and osteocyte viability. Bone 2011, 49:50-55.

16. Eastell R, Walsh JS, Watts NB, Siris E: Bisphosphonates for postmenopausal osteoporosis. Bone 2011, 49:82-88.

17. Le Goff B, Berthelot JM, Maugars Y, Romas E: Alternative use of bisphosphonate therapy for rheumatic disease. Curr Pharm Des 2010, 16:3045-3052.

18. Bilezikian JP: Efficacy of bisphosphonates in reducing fracture risk in postmenopausal osteoporosis. Am J Med 2009, 122 (2 Suppl):S14-21.

19. Brandi ML: Sustained vertebral antifracture efficacy of oral antiosteoporotic therapies in postmenopausal osteoporosis. Curr Med Res Opin 2010, 26:2553-2563. 
20. Zhong ZM, Chen JT: Anti-fracture efficacy of risedronic acid in men: A meta-analysis of randomized controlled trials. Clin Drug Investig 2009, 29:349-357.

21. Meunier PJ, Arlot M, Chavassieux P, Yates AJ: The effects of alendronate on bone turnover and bone quality. Int J Clin Pract Supp/ 1999, 101:14-17.

22. Eastell R, Hannon RA: Biomarkers of bone health and osteoporosis risk. Proc Nutr Soc 2008, 67:157-162.

23. Bergmann P, Body JJ, Boonen S, Boutsen Y, Devogelaer JP, Goemaere S, Kaufman JM, Reginster JY, Gangji V: Evidence-based guidelines for the use of biochemical markers of bone turnover in the selection and monitoring of bisphosphonate treatment in osteoporosis: a consensus document of the Belgian Bone Club. Int J Clin Pract 2009, 63:19-26.

24. Cummings SR, Karpf DB, Harris F, Genant HK, Ensrud K, LaCroix AZ, Black DM: Improvement in spine bone density and reduction in risk of vertebral fractures during treatment with antiresorptive drugs. Am J Med 2002, 112:281-289.

25. Ettinger B, Black DM, Mitlak BH, Knickerbocker RK, Nickelsen T, Genant HK, Christiansen C, Delmas PD, Zanchetta JR, Stakkestad J, Glüer CC, Krueger K, Cohen FJ, Eckert S, Ensrud KE, Avioli LV, Lips P, Cummings SR: Reduction of vertebral fracture risk in postmenopausal women with osteoporosis treated with raloxifene: results from a 3-year randomized clinical trial. Multiple Outcomes of Raloxifene Evaluation (MORE) Investigators. JAMA 1999, 282:637-645.

26. Liberman UA, Weiss SR, Broll J, Minne HW, Quan H, Bell NH Rodriguez-Portales J, Downs RW Jr, Dequeker J, Favus M: Effect of oral alendronate on bone mineral density and the incidence of fractures in postmenopausal osteoporosis. The Alendronate Phase III Osteoporosis Treatment Study Group. N Engl J Med 1995, 333:1437-1443.

27. Riggs BL, Melton $L$ J 3rd, O'Fallon WM: Drug therapy for vertebral fractures in osteoporosis: evidence that decreases in bone turnover and increases in bone mass both determine antifracture efficacy. Bone 1996, 18(3 Suppl):197S-201S

28. Fraser LA, Vogt KN, Adachi JD, Thabane L: Fracture risk associated with continuation versus discontinuation of bisphosphonates after 5 years of therapy in patients with primary osteoporosis: a systematic review and meta-analysis. Ther Clin Risk Manag 2011, 7:157-166.

29. Rodan G, Reszka A, Golub E, Rizzoli R: Bone safety of long-term bisphosphonate treatment. Curr Med Res Opin 2004, 20:1291-1300.

30. Pazianas M, Abrahamsen B: Safety of bisphosphonates. Bone 2011, 49:103-110

31. Beck TJ, Ruff CB, Shaffer RA, Betsinger K, Trone DW, Brodine SK: Stress fracture in military recruits: gender differences in muscle and bone susceptibility factors. Bone 2000, 27:437-444

32. Pohl MB, Mullineaux DR, Milner CE, Hamill J, Davis IS: Biomechanical predictors of retrospective tibial stress fractures in runners. J Biomech 2008, 41:1160-1165.

33. Tommasini SM, Nasser P, Schaffler MB, Jepsen KJ: Relationship between bone morphology and bone quality in male tibias: implications for stress fracture risk. J Bone Miner Res 2005, 20:1372-1380.

34. Allen MR, Burr DB: Bisphosphonate effects on bone turnover, microdamage, and mechanical properties: what we think we know and what we know that we don't know. Bone 2011, 49:56-65.

35. Allen MR, Follet H, Khurana M, Sato M, Burr DB: Antiremodeling agents influence osteoblast activity differently in modeling and remodeling sites of canine rib. Calcif Tissue Int 2006, 79:255-261.

36. Allen MR, Reinwald S, Burr DB: Alendronate reduces bone toughness of ribs without significantly increasing microdamage accumulation in dogs following 3 years of daily treatment. Calcif Tissue Int 2008, 82:354-360.

37. Tang SY, Allen MR, Phipps R, Burr DB, Vashishth D: Changes in non-enzymatic glycation and its association with altered mechanical properties following 1 -year treatment with risedronate or alendronate. Osteoporos Int 2009, 20:887-894

38. Mashiba T, Hirano T, Turner CH, Forwood MR, Johnston CC, Burr DB: Suppressed bone turnover by bisphosphonates increases microdamage accumulation and reduces some biomechanical properties in dog rib. $J$ Bone Miner Res 2000, 15:613-620.

39. Tjhia CK, Odvina CV, Rao DS, Stover SM, Wang X, Fyhrie DP: Mechanical property and tissue mineral density differences among severely suppressed bone turnover (SSBT) patients, osteoporotic patients, and normal subjects. Bone 2011, 49:1279-1289

40. Boskey AL, Donnelly E, Kinnett JG: Bone quality: from bench to bedside: opening editorial comment. Clin Orthop Relat Res 2011, 469:2087-2089.

41. Ito M, Nakata T, Nishida A, Uetani M: Age-related changes in bone density, geometry and biomechanical properties of the proximal femur: CT-based 3D hip structure analysis in normal postmenopausal women. Bone 2011, 48:627-630.

42. Melton LJ 3rd, Riggs BL, Keaveny TM, Achenbach SJ, Hoffmann PF, Camp JJ, Rouleau PA, Bouxsein ML, Amin S, Atkinson EJ, Robb RA, Khosla S: Structural determinants of vertebral fracture risk. J Bone Miner Res 2007, 22:1885-1892.

43. Lenart BA, Lorich DG, Lane JM: Atypical fractures of the femoral diaphysis in postmenopausal women taking alendronate. N Engl J Med 2008, 358:1304-1306.

44. Takakuwa M, Iwamoto J, Konishi M, Zhou Q, Itabashi K: Risedronate improves proximal femur bone density and geometry in patients with osteoporosis or osteopenia and clinical risk factors of fractures: a practicebased observational study. J Bone Miner Metab 2011, 29:88-95.

45. Hochberg MC, Rizzoli R: Long-term experience with alendronate in the treatment of osteoporosis. Expert Opin Pharmacother 2006, 7:1201-1210

46. Unnanuntana A, Ashfaq K, Ton QV, Kleimeyer JP, Lane JM: The effect of longterm alendronate treatment on cortical thickness of the proximal femur. Clin Orthop Relat Res 2012, 470:291-298.

47. Koh JS, Ng AC, Png MA, Howe TS: Letter to the editor: the effect of longterm alendronate treatment on cortical thickness of the proximal femur. Clin Orthop Relat Res 2011, 469:3509-3510; author reply 3511-3512.

48. Chavassieux P, Seeman E, Delmas PD: Insights into material and structural basis of bone fragility from diseases associated with fractures: how determinants of the biomechanical properties of bone are compromised by disease. Endocr Rev 2007, 28:151-164.

49. Donnelly E, Meredith DS, Nguyen JT, Gladnick BP, Rebolledo BJ, Shaffer AD, Lorich DG, Lane JM, Boskey AL: Reduced cortical bone compositional heterogeneity with bisphosphonate treatment in postmenopausal women with intertrochanteric and subtrochanteric fractures. J Bone Miner Res 2012, 27:672-678.

50. Vashishth D: The role of the collagen matrix in skeletal fragility. Curr Osteoporos Rep 2007, 5:62-66.

51. Banse X, Sims TJ, Bailey AJ: Mechanical properties of adult vertebral cancellous bone: correlation with collagen intermolecular cross-links. J Bone Miner Res 2002, 17:1621-1628.

52. Paschalis EP, Tatakis DN, Robins S, Fratzl P, Manjubala I, Zoehrer R, Gamsjaeger S, Buchinger B, Roschger A, Phipps R, Boskey AL, Dall'Ara E, Varga P, Zysset P, Klaushofer K, Roschger P: Lathyrism-induced alterations in collagen crosslinks influence the mechanical properties of bone material without affecting the mineral. Bone 2011, 49:1232-1241.

53. Wang X, Shen X, Li X, Agrawal CM: Age-related changes in the collagen network and toughness of bone. Bone 2002, 31:1-7.

54. Durchschlag E, Paschalis EP, Zoehrer R, Roschger P, Fratzl P, Recker R, Phipps R, Klaushofer K: Bone material properties in trabecular bone from human iliac crest biopsies after 3- and 5-year treatment with risedronate. J Bone Miner Res 2006, 21:1581-1590.

55. O'Brien FJ, Brennan O, Kennedy OD, Lee TC: Microcracks in cortical bone: how do they affect bone biology? Curr Osteoporos Rep 2005, 3:39-45

56. Chapurlat RD, Arlot M, Burt-Pichat B, Chavassieux P, Roux JP, Portero-Muzy N, Delmas PD: Microcrack frequency and bone remodeling in postmenopausal osteoporotic women on long-term bisphosphonates: a bone biopsy study. J Bone Miner Res 2007, 22:1502-1509.

57. Miller LM, Little W, Schirmer A, Sheik F, Busa B, Judex S: Accretion of bone quantity and quality in the developing mouse skeleton. $J$ Bone Miner Res 2007, 22:1037-1045.

58. Gourion-Arsiquaud S, Faibish D, Myers E, Spevak L, Compston J, Hodsman A, Shane E, Recker RR, Boskey ER, Boskey AL: Use of FTIR spectroscopic imaging to identify parameters associated with fragility fracture. J Bone Miner Res 2009, 24:1565-1571

59. Gamsjaeger S, Buchinger B, Zwettler E, Recker R, Black D, Gasser JA, Eriksen EF, Klaushofer K, Paschalis EP: Bone material properties in actively boneforming trabeculae in postmenopausal women with osteoporosis after three years of treatment with once-yearly Zoledronic acid. J Bone Miner Res 2011, 26:12-18

60. Boskey AL, Spevak L, Weinstein RS: Spectroscopic markers of bone quality in alendronate-treated postmenopausal women. Osteoporos Int 2009, 20:793-800.

61. Gourion-Arsiquaud S, Allen MR, Burr DB, Vashishth D, Tang SY, Boskey AL: Bisphosphonate treatment modifies canine bone mineral and matrix 
properties and their heterogeneity. Bone 2010, 46:666-672.

62. Boivin GY, Chavassieux PM, Santora AC, Yates J, Meunier PJ: Alendronate increases bone strength by increasing the mean degree of mineralization of bone tissue in osteoporotic women. Bone 2000, 27:687-694.

63. Nuzzo S, Lafage-Proust MH, Martin-Badosa E, Boivin G, Thomas T, Alexandre C, Peyrin F: Synchrotron radiation microtomography allows the analysis of three-dimensional microarchitecture and degree of mineralization of human iliac crest biopsy specimens: effects of etidronate treatment. J Bone Miner Res 2002, 17:1372-1382

64. Ott SM: What is the optimal duration of bisphosphonate therapy? Cleveland Clin J Med 2011, 78:619-630.

65. Odvina CV, Levy S, Rao S, Zerwekh JE, Rao DS: Unusual mid-shaft fractures during long-term bisphosphonate therapy. Clin Endocrinol (Oxf) 2010, 72:161-168
66. Somford MP, Draijer FW, Thomassen BJ, Chavassieux PM, Boivin G, Papapoulos SE: Bilateral fractures of the femur diaphysis in a patient with rheumatoid arthritis on long-term treatment with alendronate: clues to the mechanism of increased bone fragility. $J$ Bone Miner Res 2009, 24:1736-1740.

67. Aspenberg P, Schilcher J, Fahlgren A: Histology of an undisplaced femoral fatigue fracture in association with bisphosphonate treatment. Frozen bone with remodelling at the crack. Acta Orthop 2010, 81:460-462.

doi:10.1186/ar4013

Cite this article as: ven der Meulen MCH, Boskey AL: Atypical subtrochanteric femoral shaft fractures: role for mechanics and bone quality. Arthritis Research \& Therapy 2012, 14:220 